\title{
Sistema de gestão por competência em pequena empresa
}

\author{
Vanessa Santos de Oliveira Especialista em Gestão de Pessoas, Rádio e TV Sergipe, Brasil - vannessaoliveira15@gmail.com \\ Monica Cristina Rovaris Machado Doutoranda em Administração, Universidade do Vale do Itajaí (UNIVALI), Brasil - monicarovarisdoutorado@gmail.com \\ Elaine John Doutoranda em Administração, Universidade do Vale do Itajaí (UNIVALI), Brasil - elaine_j8@hotmail.com
}

\begin{abstract}
RESUMO
A implantação do Sistema de Gestão por Competência é uma ferramenta moderna da gestão de pessoas, que engloba desde o procedimento gerencial, da migração dos cargos e funções até a validação dos resultados desejados. $O$ estudo ora apresentado propõe a implantação do modelo de gestão por competência na empresa Alfa, considerada de pequeno porte. A pesquisa foi realizada por meio da metodologia qualitativa e descritiva, a estratégia de estudo de caso único, com técnica de coleta de dados a entrevista semiestruturada, observação direta e análise de documentos. Conclui-se que, a gestão por competência é resultado do processo construído por meio das informações levantadas na organização que serviram para aplicação de teorias aqui desenvolvidas, demonstrando o interesse na aprendizagem para adequação das competências e melhorias no desempenho dos colaboradores, transparência nas relações de trabalho, por meio da participação dos envolvidos no processo de mapeamento na organização.
\end{abstract}

Palavras-Chave: Gestão de Pessoas. Gestão por Competência. Pequena Empresa. Estudo de Caso. Mapeamento.

\section{Competence management system in a small business}

\begin{abstract}
The introduction of the system of management of competences is a modern tool of people management which encompasses the management procedure, migration of posts and functions as well as the validation of expected results. The presented study proposes the model of management based on competence in the enterprise Alfa, considered a small enterprise. The research was carried through qualitative and descriptive methodology. The strategy applied was that of a single case study with collection of data through semi structured interview, direct observation and analysis of documents. The conclusion was that management based on competence is the result of the process built through the information gathered in the organization which applied to theories here developed. The results demonstrate interest in the learning process for adaptation of competences and improvement in the performance of the collaborators, transparency in work relations, through the participation of those involved in the process of mapping in the organization.
\end{abstract}

Keywords: People Management. Competence Management. Small Business. Case Study. Mapping. 


\section{INTRODUÇÃO}

As mudanças e inovações nas organizações fazem com que as mesmas se deparem com um mercado sem fronteiras, altamente dinâmico e, de forma contínua, torna-as cada vez mais competitivas, provocando o surgimento de novos modelos que se adequem aos avanços tecnológicos na administração. A valorização dos colaboradores, perante um bom relacionamento da organização junto com os funcionários, gera crescimento na valorização do capital humano, contribuindo para novas formas de gestão e seleção de pessoal (DUTRA, 2012). Uma das possibilidades para que as organizações alcancem vantagem competitiva é o aproveitamento das competências das pessoas que nelas atuam.

Nesse aspecto o sistema de gestão por competência auxilia no processo gerencial, adaptando as aptidões e habilidades humanas para o alcance dos resultados desejados. Pode ser feita a partir de um padrão, mapeando competências organizacionais e profissionais de uma maneira a adaptarem-se às competências que a organização e seus colaboradores têm e que necessitarão ser desenvolvidas para que alcancem os resultados necessários tendo em vista o crescimento da organização, migrando, portanto, o modelo de gestão de pessoas utilizado até então pela organização.

Nas organizações brasileiras, desde a década de 1990, conhecida como a década dos serviços e das competências, notou-se o interesse mais aprofundado nos conhecimentos e informações e a valorização da capacidade, intensificando o investimento em capacitação, seja enviando os seus funcionários para participar de eventos ou até mesmo custeando a formação para os seus colaboradores. Diversos campos da economia tornaram-se mundialmente muito competitivos, exigindo flexibilidade, rapidez e o desenvolvimento da capacidade de inovações das pessoas (GRAMIGNA, 2002).

O grau de satisfação das expectativas e das necessidades da empresa em relação aos colaboradores, por meio do mapeando das competências organizacionais e profissionais, busca-se o desenvolvimento o conhecimento, a habilidade e a atitude (CHA), competências que são fontes por excelência para a aquisição de vantagem competitiva, sustentável para as organizações (CARBONE, 2006).

O processo de implantação da gestão de competências nas empresas muitas vezes está na resistência dos níveis superiores, no entanto, os obstáculos podem ser ultrapassados por meio de sensibilização e discussões sobre um novo modelo de gestão, possibilitando desta forma a interação entre os objetivos individuais e organizacionais (FRANÇA, 2009; GIL, 2010).

O conceito de competência é um tema muito discutido nas organizações que busca vincular a estratégia organizacional com as competências, dando foco para a gestão de pessoas (FLEURY; FLEURY, 2004; DUTRA, 2004). Os colaboradores são considerados agentes de mudanças, deixando de ter funções habituais e formais e vistos como impulsionadores dos resultados, aperfeiçoando a capacidade de modificações dentro da empresa e buscando o seu crescimento profissional.

O presente artigo tem como objetivo propor um modelo de competências para o desempenho das funções de trabalho e gestão em uma empresa de pequeno porte, visando o atingimento de resultados compatíveis à sustentabilidade organizacional, tornando-a competitiva. O tema desta pesquisa é a Gestão por Competência em uma empresa de pequeno porte no nordeste do Brasil.

Essa pesquisa tem como objetivo propor um modelo de gestão por competência visando o desenvolvimento da empresa Alfa Ltda. A partir da definição do modelo de gestão de competências, desenvolver-se-á o mapeamento das competências profissionais de modo a identificar os requisitos necessários para que seus colaboradores possam desempenhar as atividades na organização, e que deverão ser desenvolvidas para a realização de projetos visando o crescimento da organização. Delineia-se como pergunta de pesquisa: De que forma pode ser proposto um modelo de gestão por competência visando o desenvolvimento na empresa Alfa?

O artigo se estrutura da seguinte forma: após a introdução, é apresentada a revisão bibliográfica que buscou a base teórica para as análises desta pesquisa, os conceitos e tipologias sobre gestão de pessoas e o modelo de competências. A seguir, delineia-se a metodologia utilizada na pesquisa. No capítulo 4, é apresentado o caso utilizado como objeto de pesquisa, para posteriormente mostrar os resultados e conclusões, seguido ainda pelas referências utilizadas.

\section{FUNDAMENTAÇÃO TEÓRICA}

Esta parte do artigo dedica-se a delinear os principais conceitos e definições referente ao tema de estudo, como: gestão de pessoas e micro e pequenas empresas, além de comentários, interpretações e reflexões, buscando atender aos objetivos propostos.

\subsection{Gestão de Pessoas}

A denominação "Gestão de Pessoas" veio substituir e ser utilizada no lugar de "Recursos Humanos", e vem buscar pelo crescimento com menor custo, assumindo o papel de adequar às mudanças ocorridas em uma organização. A 
maneira como as organizações gerenciam as pessoas, ocorrem alterações que se baseiam em modelos tradicionais, onde não atendem mais as necessidades das pessoas e das empresas (DUTRA, 2008a).

Atualmente no Brasil, as empresas estão obtendo bons resultados em gestão de pessoas, tendo aplicado os conceitos de competência, destacando conjunto de políticas e práticas de gestão de pessoas (DUTRA, 2012).

França (2009, p. 3) diz que a gestão de pessoas é "analisada pelos enfoques comportamental e administrativo relacionando-se com os mais variados espaços organizacionais, sendo novas tecnologias, reduções ou novas posições na empresa". Cabendo aos profissionais de gestão de pessoas selecionar e escolher os mais adequados para determinadas funções, considerando na maioria dos casos, não a qualidade atual do candidato e sim o potencial para aquela determinada função, unindo sua vontade de trabalhar e aprender, compreende que seus objetivos são entendidos como uma abordagem sistêmica, como proporcionar competitividade à organização, desenvolver e manter a qualidade de vida no trabalho, administrar a mudança, aumentar a autoavaliação e a satisfação dos empregados no ambiente de trabalho e ajudar a organização a alcançar seus objetivos e metas (FRANÇA, 2009; GIL, 2010)

A Gestão por Competência, encontra-se presente nas práticas organizacionais, baseando os modelos viventes de gestão. A rapidez dos dias atuais também exige velocidade nas decisões empresariais, conquistando o alinhamento do desempenho das pessoas com as estratégias e as transformações intensas e estáveis do mercado. Portanto gestão por competência deve estar alinhada às estratégias da organização, ou seja, sendo um processo contínuo.

As competências envolvem a aquisição, integração e a transmissão de conhecimentos e habilidades e recursos que agregam valor econômico a organização e valor social ao indivíduo (FLEURY; FLEURY, 2006). Os diversos significados de competência recomendam que o indivíduo possua disposição de compreender determinados casos e de resolver algumas atitudes perante esta. E o desenvolvimento deste conceito no âmbito organizacional é apresentado por meio da gestão por competência a sua relevância no desempenho das atividades empresariais e no que atribui ao desenvolvimento humano.

Perrenoud (2000) define Competência como a mobilização correta, rápida, pertinente e criativa de múltiplos recursos cognitivos (saberes, informações, valores, atitudes, habilidades, inteligências, esquemas de percepção, de avaliação e de raciocínio), e a transição para o conceito de competências pode ser ligada aos impactos das transformações recentes no ambiente de negócios e a necessidade de adaptar-se às mudanças estruturais na organização do trabalho. Em outras palavras, a competência remete a mobilização de recursos pelas organizações e pelas pessoas.

Durand (2000 apud BORGES-ANDRADE; ABBAD; MOURÃO, 2006), afirma que competências são desenvolvidas por meio da aprendizagem adquirindo o $\mathrm{CHA}$ (conhecimento, habilidade e atitudes) com os objetivos organizacionais, conforme mostra a figura 1.

Figura 1 - As dimensões da competência

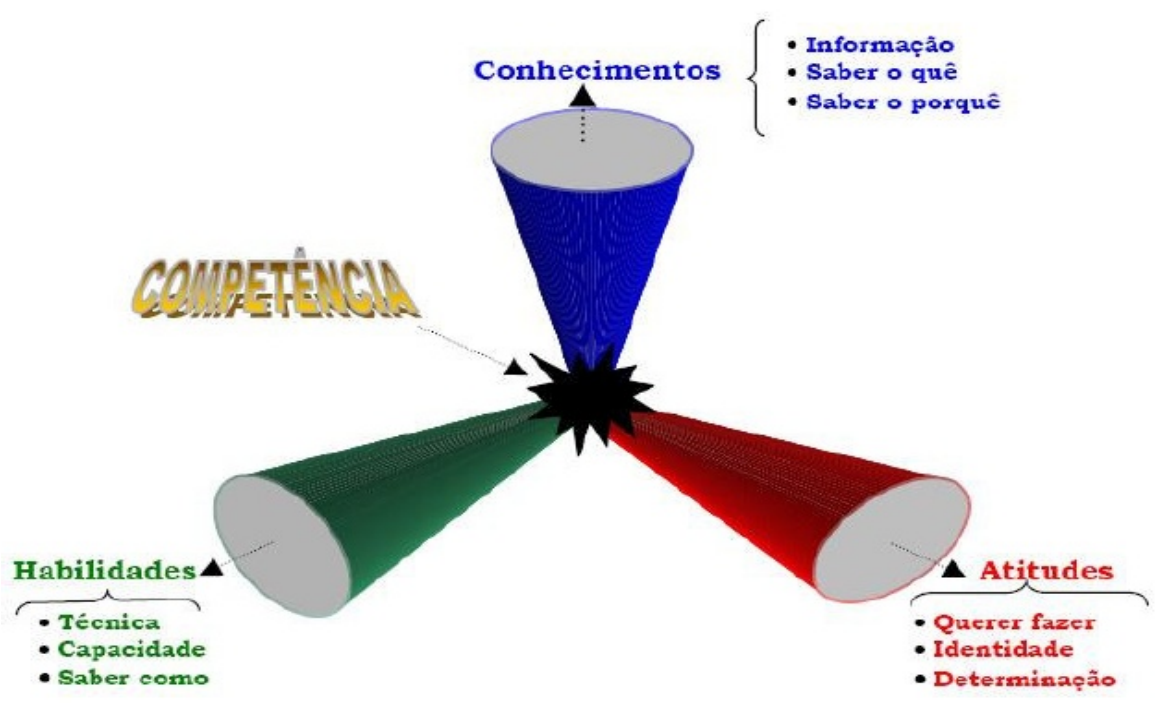

Fonte: Adaptado Durand (2000 apud BRANDÃO; GUIMARÃES, 2001, p. 19).

Dutra (2004, p. 25) diz que "habilidade é arte de saber fazer, envolve proficiências práticas, físicas e mentais e são adquiridas através de treinamentos e práticas, incluindo o conhecimento de regras de procedimentos e a habilidade de se comunicar". Portanto, conhecimento envolve os dados, ou seja, as informações necessárias para atingir algum propósito. As habilidades abrangem determinada aptidão para execução, permitindo executar o projeto. As atitudes são imprescindíveis para que o projeto aconteça, ou seja, concretize. Enfim, finaliza quando a empresa somente é 
reconhecida se a competência for considerada um fator essencial para o desenvolvimento e crescimento, caso contrário, não haverá sentido em priorizar a gestão por competência.

Já na visão de Leme (2005, p. 17), conceitua competência como:

Um agrupamento de conhecimentos, habilidades e atitudes correlacionadas, que afeta parte considerável da atividade de alguém, que se relaciona com o seu desempenho, que pode ser medido segundo padrões preestabelecidos, e que pode ser melhorado por meio de treinamento e desenvolvimento.

Rodriguez y Rodriguez (2002) afirma que a essência da competência se compreende nas letras: CHA, que tem como significado.

Conhecimento é o saber. Aprende-se em diversos lugares, porém é pouco colocado em prática; Habilidade é o saber a fazer. É utilizada do conhecimento a prática; Atitude é o querer fazer. É proporcionado pela vontade de fazer, pela garra. É o poder de querer resolver determinada situação como o apoio do conhecimento e da habilidade (RODRIGUEZ Y RODRIGUEZ, 2002, p. 26).

Na visão de Rodriguez y Rodriguez (2002), as competências organizacionais são processos, funções, tecnologias e pessoas que tornam possíveis a uma empresa entregar produtos e serviços com alta qualidade, com velocidade, eficiência e um serviço ao cliente de elevado nível. A gestão de competências tem ocupado partes das empresas, perante suas estratégias. Embora tenham alguns conceitos, sempre um completando o outro.

Segundo Dutra (2008b, p. 24), "o estabelecimento das competências individuais deve estar vinculado à reflexão sobre as competências organizacionais, pois elas se influenciam mutuamente". Portanto, algo de fácil compreensão por parte das pessoas, sendo que, há dificuldades na influência mútua, que compreende a mudança das competências organizacionais e as atividades no dia a dia.

Para Vilas Boas e Andrade (2009) as competências individuais, ou humanas ou profissionais são características que o funcionário deve possuir para auxiliar a empresa no cumprimento de seus objetivos, constituindo como base para as competências organizacionais. Os modelos de gestão por competência são o desenvolvimento das aptidões dos colaboradores aumentando a capacidade ao dispor da empresa. Para Fleury e Fleury (2011), há quatro tipos de competências organizacionais, conceituados como: competências essenciais, competências distintivas, competências organizacionais e competências individuais, conforme mostra a Quadro 1.

Quadro 1- Níveis de Competências Organizacionais

\begin{tabular}{|l|l|}
\hline Competências Essenciais & Competências e atividades mais elevadas no nível corporativo. \\
\hline Competências Distintivas & $\begin{array}{l}\text { Competências e atividades que os clientes reconhecem como } \\
\text { diferenciadores de seus concorrentes. }\end{array}$ \\
\hline Competências Individuais & $\begin{array}{l}\text { Saber agir, que implica mobilizar, integrar, transferir } \\
\text { conhecimento, recursos e habilidades, que agregam valor à } \\
\text { empresa e valor social ao indivíduo. }\end{array}$ \\
\hline Competências Organizacionais & $\begin{array}{l}\text { Competências coletivas associadas às atividades e atividades } \\
\text { fins. }\end{array}$ \\
\hline
\end{tabular}

Fonte: Fleury e Fleury (2011, p. 34).

As competências essenciais são destacadas por Hamel e Prahalad (1995, p. 227) como ingrediente fulcral para ampliar a competitividade de uma empresa, pois propiciam a abertura de portas para as oportunidades do amanhã. $\mathrm{O}$ mesmo autor ainda reforça dizendo, que "um conjunto de habilidades e tecnologias, e não uma única habilidade ou tecnologia isolada".

A integração é a marca de autenticidade das competências essenciais. Uma competência específica de uma organização representa a soma do aprendizado de todos os conjuntos de habilidades tanto em nível pessoal quando de unidade organizacional. Portanto, é muito pouco provável que uma competência essencial se baseie inteiramente em um único indivíduo ou em uma pequena equipe. (HAMEL; PRAHALAD 1995, p. 233-234) .

Na gestão por competência, o compromisso e as aptidões direcionadas para o alcance dos resultados é explicado por Carvalho (2011, p. 325) "Gestão por competência consiste no que identifica as competências indispensáveis, incluindo conhecimentos e habilidades da eficiência e eficácia profissional, além de apontar as falhas ou deficiências de qualificação para atividades ou serviços especiais".

Para Gramigna (2007), o mapeamento das competências é a etapa definitiva para o desenvolvimento do modelo na organização e necessita da participação da direção da empresa como fator fundamental de sucesso. São apontados dois tipos de competências: a técnica, que são as competências necessárias que o profissional precisa obter para realizar determinada função, e a de suporte que são as competências que diferenciam o profissional, que visam agregar valor ao trabalho. 
Já as competências comportamentais, são aquelas que possibilitam probabilidade para obter sucesso na execução de determinadas atividades. As categorias representativas de atitudes, conhecimentos e habilidades, foram representados graficamente empregando a metáfora da "árvore das competências" (GRAMIGNA, 2002).

Portanto, as raízes correspondem às atitudes, o tronco ao conhecimento e a copa (frutos, flores e folhas) que corresponde às habilidades, conforme ilustra a figura 2.

Figura 2 - Árvore das competências funcionais

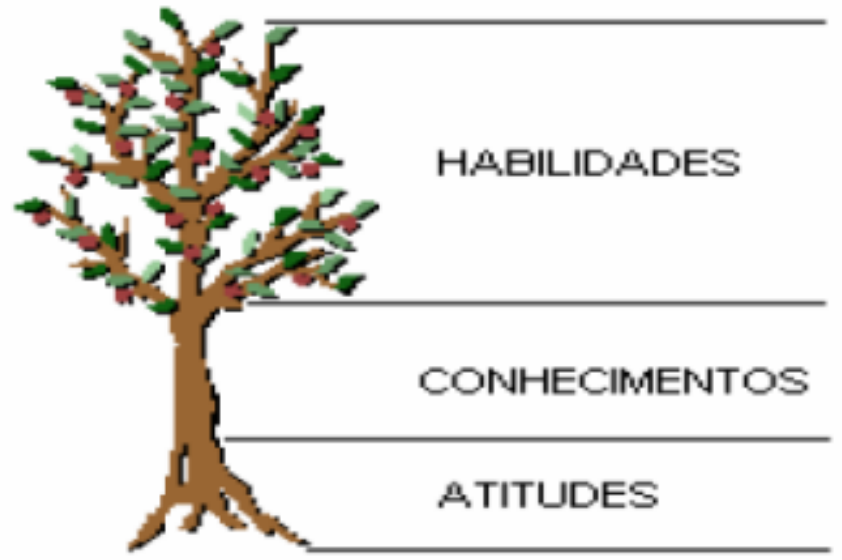

Fonte: Adaptado de Gramigna (2002).

A figura ilustra o posicionamento das competências humanas, o modelo de árvore das competências ajuda aos gestores a selecionar as capacidades que são de importância para as empresas. Para Gramigna (2002) a junção entre a composição da árvore, com as competências humanas, as partes adaptam a raiz (são valores, crenças e princípios adquiridos na sua vivência, que interferem no grau de envolvimento e empenho no trabalho, equivalem às atitudes); o tronco (informações armazenadas pela pessoa, que utiliza de acordo com as suas necessidades, os conhecimentos); a copa (agir com talento, capacidade técnica, para obtenção de resultados positivos, as habilidades).

O modelo utilizado no presente artigo foi o modelo de Árvore das Competências definida por Gramigna (2002), que apresenta a competência essencial, que é a característica da empresa, que agrega valor ao serviço oferecido por ela, competências organizacionais, que são as capacidades e características determinantes das empresas para o alcance de vantagem competitiva, e por fim as competências individuais dos colaboradores, que buscam identificar as características necessárias que um colaborador deve ter para exercer determinada função de maneira que agrega valor para empresa.

\subsection{MICRO E PEQUENAS EMPRESAS}

$\mathrm{Na}$ realidade brasileira, um dos maiores desafios para as pequenas e médias empresas é sobrevivência e crescimento do negócio. A economia cada vez mais globalizada gera disputa por novos mercados que transcendem os limites territoriais e locais, fazendo com que as organizações busquem se adequar às novas tendências, objetivando manter sua competitividade.

Entretanto, em recentes pesquisas também realizadas pelo Serviço de Apoio às Micro e Pequenas Empresas (SEBRAE, 2007a), constata-se que um dos principais motivos para o encerramento das atividades das empresas de pequeno e médio porte no Brasil é a falta de planejamento.

As micro e pequenas empresas representam um pilar fundamental para a economia do país, desempenhando um papel de suma importância para o desenvolvimento da nação. Destaca-se também sua importância para o crescimento da economia dos municípios, principalmente para os localizados fora das regiões metropolitanas. Um dos critérios mais utilizados é o da ocupação de mão de obra por estabelecimento (SEBRAE, 2014)

Segundo ainda a pesquisa realizada pela entidade, são classificadas microempresas comerciais as que possuem até nove empregados e pequenas as que possuem de 10 a 49 pessoas ocupadas, conforme exposto no quadro 2. 
Quadro 2 - Classificação quanto ao número de pessoas ocupadas

\begin{tabular}{|l|l|l|l|}
\multicolumn{1}{|c|}{ Porte / Setor } & \multicolumn{1}{c|}{ Indústria } & \multicolumn{1}{c|}{ Comércio } & \multicolumn{1}{c|}{ Serviços } \\
\hline Microempresa & Até 19 & Até 9 & Até 9 \\
\hline Pequena Empresa & De 20 a 99 & De 10 a 49 & De 10 a 49 \\
\hline Média empresa & De 100 a 499 & De 50 a 99 & De 50 a 99 \\
\hline
\end{tabular}

Fonte: SEBRAE (2014)

Conforme estudos realizados pelo SEBRAE (2007a), as micro e pequenas empresas vêm alcançando uma importância cada vez maior na economia de nosso país. O impacto econômico no que se refere a mudança do cenário afeta as pequenas e médias empresas de forma a mudar muitas vezes o rumo dos negócios. Com base em uma pesquisa do SEBRAE (2007b), as Micro e Pequenas Empresas (MPEs) representam 20\% do Produto Interno Bruto (PIB) nacional e correspondem a $99,2 \%$ das 4,1 milhões de empresas formais na indústria, comércio e serviços, além de conter $45 \%$ da força de trabalho que possui carteira assinada.

\section{METODOLOGIA}

O presente artigo utilizou a metodologia qualitativa, permitindo a realização de estudos aprofundados sobre uma ampla variedade de tópicos (YIN, 2015). Quanto aos fins, definida como descritiva, pois descreve determinado contexto/fenômeno, podendo-se estabelecer relações entre variáveis e as categorias analíticas e definindo sua natureza (TRIVIÑOS, 1987; VERGARA, 2000; RICHARDSON, 2009). Quanto aos meios, a pesquisa é um estudo de caso do tipo único, pois são encontrados com maior frequência entre as pesquisas sociais, podendo elaborar explicações causais para a compreensão de processos específicos em contextos definidos (GIALDINO, 2014). Além disso, sua utilização objetiva uma análise contextual completa de poucos fatos ou condições e suas inter-relações, permitindo a obtenção de informações valiosas adquiridas através dos detalhes das informações (COOPER; SCHINDLER, 2006).

$O$ presente estudo teve como objeto de pesquisa uma organização classificada como pequena empresa em função da quantidade de pessoas ocupadas, entre 10 e 49 (SEBRAE, 2014). A pesquisa ainda contou com apoio de dados secundários por meio de pesquisa em documentos da organização e banco de dados disponibilizados pela empresa. A pesquisa foi validada por meio da triangulação entre entrevista semiestruturada, utilizada para obter informações a respeito de determinado assunto, mediante uma conversação de natureza profissional, sendo amplamente utilizada em investigação social, para a coleta de dados ou para ajudar no diagnóstico ou no tratamento de um problema social (MARCONI; LAKATOS, 2002), observação direta, utilizada como avaliação de incidências de certos tipos de comportamentos durante certos períodos de tempo no campo (YIN, 2005) por meio de visitas visando a coleta de dados no momento da sua realização, e análise de documentos que pode assumir muitas formas e devem ser o objeto de planos explícitos da coleta de dados nas organizações por apresentarem dados e informações relativos ao dia a dia da organização (YIN, 2005).

A análise de dados teve como base a análise de conteúdo pois permite abordar atitudes, valores, representações, mentalidades e ideologias e conserva a forma literal dos dados, atendo-se às evidências existentes entre as unidades e as categorias adotadas (LAVILLE; DIONNE, 1999; GIALDINO, 2014). As etapas que constituíram a pesquisa foram: a aquisição do material (entrevista semiestruturada), a coleta de dados; aplicação da entrevista; avaliação das respostas obtidas; análise dos resultados; elaboração de relatório e apresentação dos resultados.

A partir do objetivo de pesquisa proposto, buscou-se delinear o Modelo de Gestão por Competência, avaliando as contribuições de mapeamentos de competências em um modelo de gestão por competência na empresa Alfa, delineando-se os requisitos da empresa, visando suprir suas necessidades, como mostra a Quadro 3. 
Quadro 3 - Demonstrativo das variáveis e elementos de análise

\begin{tabular}{|c|c|c|}
\hline Dimensões & Categorias de análise & Elementos de análise \\
\hline $\begin{array}{c}\text { Características dos } \\
\text { Gestores }\end{array}$ & Perfil dos Gestores & $\begin{array}{l}\text { Sexo } \\
\text { Faixa Etária } \\
\text { Escolaridade } \\
\text { Tempo de Empresa }\end{array}$ \\
\hline $\begin{array}{l}\text { Produtos do } \\
\text { Planejamento } \\
\text { Estratégico }\end{array}$ & $\begin{array}{l}\text { Fases do } \\
\text { desenvolvimento do } \\
\text { planejamento } \\
\text { estratégico }\end{array}$ & $\begin{array}{l}\text { Critérios utilizados no diagnóstico interno e externo } \\
\text { Missão } \\
\text { Visão } \\
\text { Valores } \\
\text { Planos de ação } \\
\text { Objetivos }\end{array}$ \\
\hline $\begin{array}{l}\text { Dificuldades no } \\
\text { processo }\end{array}$ & Principais Barreiras & $\begin{array}{l}\text { Motivação e/ou resistência dos funcionários } \\
\text { (Mobilização Interna) } \\
\text { Dificuldades na percepção dos gestores }\end{array}$ \\
\hline $\begin{array}{c}\text { Principais Benefícios } \\
\text { obtidos }\end{array}$ & $\begin{array}{l}\text { Benefícios na percepção } \\
\text { dos gestores }\end{array}$ & $\begin{array}{l}\text { Benefícios no desempenho organizacional } \\
\text { Benefícios obtidos na percepção dos gestores } \\
\text { Estímulos para elaboração }\end{array}$ \\
\hline
\end{tabular}

Fonte: Autores (2016).

A entrevista semiestruturada foi realizada com os gestores das áreas de Direção, Administrativa (RH, Financeiro, Fiscal/Contábil, Compras e TI) e Técnica, com o intuito de recolher informações das áreas citadas para desenvolver e aplicar uma melhoria para cada gestão. Além disso, foram divididos entre os profissionais dos cargos como: auxiliar, assistente, analista, encarregado, gerente, supervisor, técnicos e diretor das respectivas áreas, em um total de 10 entrevistados.

Após a organização dos materiais pesquisados, iniciou-se a análise de conteúdo, vinculando a categorização dos dados de acordo com as dimensões propostas no estudo. Nesta etapa foram analisadas as fontes secundárias e fontes primárias. Optou-se por esta técnica de análise, pois a mesma permite abordar atitudes, valores, representações, mentalidades e ideologias e conserva a forma literal dos dados, atendo-se às evidências existentes entre as unidades e as categorias adotadas (LAVILLE; DIONNE, 1999; GIALDINO, 2014).

\section{RESULTADOS}

Pretende-se nesta parte do artigo apresentar a empresa e o resultado da aplicação da metodologia, apresentando etapas do modelo e o resultado do mapeamento das competências na empresa estudada.

\subsection{Apresentação do caso}

A empresa Alfa Comercial Ltda, com atividade principal comércio varejista e com atividades secundárias manutenção e reparação de máquinas e equipamentos para uso geral não especificado anteriormente, comércio a varejo de peças e acessórios novos para veículos automotores e instalações de sistema de prevenção contra incêndio, com sua forma jurídica sociedade empresária limitada. Fundada em 1992, onde iniciou a história da Alfa, marcada por inovações, responsabilidade socioambiental e compromisso com os seus consumidores. Relaciona-se, em suas atividades comerciais, com aproximadamente 50 (cinquenta fornecedores) de várias cidades do Brasil, são fabricantes, distribuidores e transportadores, com quem há anos desenvolve um sistema de parceria obtendo um resultado bastante positivo.

Atualmente, a missão da empresa Alfa é ser referência onde atua oferecendo serviços de manutenção e reparos, do sistema de combate ao incêndio com qualidade, garantia e credibilidade. Sua visão é ser referência no mercado, trabalhar com eficiência e qualidade, já em médio prazo é ter uma estrutura maior, fazer interiorização e manutenção itinerante dentro de um caminhão. "Não é apenas ser mais um, é ser referência naquilo que é feito", afirma o Gestor. Seus valores são ética e transparência, comprometimento, profissionalismo e responsabilidade, eficiência, eficácia e efetividade.

A empresa apresenta uma estrutura verticalizada. A Empresa conta atualmente com um quadro funcional de 43 (quarenta e três) colaboradores, classificada como pequena empresa (SEBRAE, 2014), entre elas, as funções existentes são da área operacional que são auxiliares de mecânico, mecânicos de equipamentos, encarregado de mecânico, pessoal do apoio, motorista entregador, ajudante de motorista. E na área administrativa divide-se em: recursos humanos, finanças, caixa, contas a pagar e receber, tecnologia da informação, vendas e segurança no trabalho. 


\subsection{Entrevista com o Gestor}

Em uma primeira etapa, para levantamento de informações, foi realizada uma entrevista com o gestor da Organização, com foco na criação do negócio e experiência na área. Por meio da entrevista, o diretor ressaltou competências como: a iniciativa de abrir seu próprio negócio, paciência, automotivação, comprometimento pessoal, agilidade e espírito de equipe para buscar seu espaço no mercado.

Quando questionado se a empresa possui parcerias com outros empreendedores, o gestor respondeu que sim, há uma agência de marketing para cuidar da imagem da empresa, pois é o primeiro contato do cliente com a organização, afirma o gestor.

O Diretor afirmou ainda que a visão da empresa é ser referência no mercado, trabalhar com eficiência e qualidade, já em médio prazo é ter uma estrutura maior, é fazer interiorização e manutenção itinerante dentro de um caminhão. O diretor afirma ainda que sua principal intenção é ser referência no seu ramo de negócio. $E$ a missão da empresa é "ser referência onde atuar oferecendo serviços de manutenção e reparos, do sistema de combate ao incêndio com qualidade, garantia e credibilidade". Quando questionado quanto ao planejamento formal da empresa, o gestor diz que existe para um prazo de 5 anos, e explica que é um planejamento participativo, com metas bem definidas para todas as áreas. Salientou também que nos últimos anos houve mudanças no RH, na estrutura física da empresa, nos produtos e processos organizacionais.

No que diz respeito ao ambiente interno, o Diretor relatou suas forças e fraquezas, selecionando como principais forças: o pessoal qualificado, o marketing e produção eficiente, um ponto a relatar que ele também colocou a produção eficiente como fraqueza, respondendo com a seguinte frase, "tem muito a melhorar, investindo em equipamentos, aperfeiçoando sua equipe com as novas tendências que o mercado oferece. " No que se refere ao ambiente externo, o Diretor citou como ameaças: a concorrência explicando que "quando não trabalha de maneira correta", a mudança tecnológica, "...por um lado é oportunidade, pois traz avanços e melhorias aos equipamentos e processos de trabalho e é ameaça pois quando acaba de investir em uma mudança chega outra", e a flutuação de demanda, quanto às oportunidades citou: os clientes, os fornecedores, taxas de juros e inflação.

Outro ponto observado pelo gestor foi o comportamento estratégico, pois o mesmo centraliza suas decisões, mas aceita opiniões. Em relação ao ambiente e a comunidade, ficou em destaque que a empresa é sustentável, utilizando telhas transparentes e reutilizando a água usada na limpeza dos extintores. Há que se destacar que a empresa está em processo de parceria com uma empresa estrangeira para se adaptar às normas sustentáveis da sua área de atuação. $A$ empresa também apoia alguns atletas e obras de caridade.

A segunda etapa de entrevistas foi realizada em um grupo de 9 pessoas. Na empresa Alfa, a identificação das competências foi realizada considerando a missão e os valores da organização sendo referência onde atuar oferecendo serviços de manutenção e reparos, do sistema de combate ao incêndio com qualidade, garantia e credibilidade. Sua visão é ser referência no mercado, trabalhar com eficiência e qualidade, já em médio prazo é ter uma estrutura maior, é fazer interiorização e manutenção itinerante dentro de um caminhão. Buscando nesta análise identificar comportamentos que explicassem a ética e os valores da mesma. Com isso, identificaram-se as seguintes competências comportamentais que foram utilizadas em todas as avaliações independentemente do cargo que a pessoa ocupasse.

As competências essenciais demandam aprendizagem organizacional grupal, onde o envolvimento e o empenho de todos os colaboradores da empresa são de vital importância para o seu desenvolvimento e consolidação. Na entrevista com os responsáveis de cada área, foi observado que competências essenciais dependem da capacidade e estratégia que a organização adota para promover a integração, comunicação e a cooperação entre os setores, como o domínio de conhecimento e seu aproveitamento, com senso de oportunidade e capacidade onde representando um dos fatores mais importantes da competência pessoal, sendo observados pelos gestores a capacidade de combinar raciocínios associando as ideias e conhecimento, aptidões para encontrar soluções, resolvendo os problemas.

Na empresa Alfa a identificação da Competência Essencial foi realizada primeiramente analisando-se a missão e os valores da empresa. Nesse sentido, buscou-se identificar comportamentos que demonstrassem os desejos da organização. Sendo assim, por meio desse procedimento identificaram-se competências comportamentais que foram utilizadas em todas as avaliações independentemente do cargo que o colaborador ocupasse.

Quanto à missão, foi observado que é ser referência onde atua, oferecendo serviços de manutenção e reparos, do sistema de combate ao incêndio com qualidade, garantia e credibilidade e sua visão é ser referência no mercado, trabalhar com eficiência e qualidade, já em médio prazo é ter uma estrutura maior, é fazer interiorização e manutenção itinerante dentro de um caminhão, relata o gestor, quanto aos valores são ética e transparência, comprometimento, profissionalismo e responsabilidade, eficiência, eficácia e efetividade.

Pode-se definir que a Competência Essencial é: Comprometimento com os resultados da Organização, pois a empresa busca a contratação de pessoas comprometidas com suas responsabilidades e com seu trabalho, se destacando e apresentando diferentes soluções, estando envolvidos, sendo iniciativo e criativo, ou seja, cativar o cliente interno, que são os colaboradores, e os clientes externos. 


\subsection{Competências Organizacionais}

Cada organização possui seu próprio agrupamento de competências, expressas no seu patrimônio de conhecimentos, desenvolvidas ao longo do tempo e responsáveis pela obtenção de vantagens competitivas. A qualidade dos produtos é considerada uma competência organizacional, sendo que, segundo os entrevistados, a empresa ao oferecer o serviço satisfatório atendendo as expectativas, fidelizando adequadamente com sua imagem e seus produtos os seus clientes. A ética foi citada por todos os entrevistados, porém como um fator importantíssimo, visando garantir a boa convivência tornando a garantir o crescimento da empresa e dos colaboradores, mantendo os padrões éticos, sendo assim, gerando um bom convívio no trabalho.

Alguns entrevistados também citaram que a empresa apoia e dá suporte para que seus colaboradores busquem o aperfeiçoamento, para que assim possam acompanhar as modificações no mercado e crescer profissionalmente, dar oportunidades para o crescimento interno da empresa, abrindo e gerando oportunidades para pessoas sem experiência, mostrando ser uma empresa de respeito. As pessoas que nela trabalham, por sua vez, contêm seu conjunto particular de competências, que podem estar sendo ou não utilizadas pela organização. Tais indivíduos concretizam e contextualizam as competências organizacionais quando colocam em prática esse patrimônio de conhecimentos da organização (DUTRA, 2001), conforme mostra a Quadro 5.

Quadro 5 - Competências Organizacionais da Empresa Alfa

\begin{tabular}{|c|l|}
\hline COMPETÊNCIAS ORGANIZACIONAIS & \multicolumn{1}{c|}{ DEFINIÇÃO } \\
\hline Inovação e Flexibilidade & $\begin{array}{l}\text { Capacidade de adaptação rápida a situações } \\
\text { inesperadas e facilidade de encontrar novas soluções } \\
\text { para resolver problemas e adversidade. }\end{array}$ \\
\hline Sustentabilidade & $\begin{array}{l}\text { Definir ações e atividades que visam suprir as } \\
\text { necessidades atuais dos seres humanos, sem } \\
\text { comprometer o futuro das próximas gerações. }\end{array}$ \\
\hline Foco nos clientes e resultados & $\begin{array}{l}\text { Capacidade de tomar providências rápidas diante de } \\
\text { problemas, conflitos, visando o melhor atendimento das } \\
\text { necessidades do cliente. }\end{array}$ \\
\hline
\end{tabular}

Fonte: Autores (2016).

Ao fazer uma comparativo com as respostas dadas pelos entrevistados, pode-se observar que algumas competências citadas acima, foram baseadas nas ações e comprometimento que a empresa tem e passa para cada um que vivencia. Outro ponto que chamou bastante atenção foi à competência sustentabilidade, onde o Diretor afirma que "Trabalha com telhas transparente e reutiliza a água usada na limpeza dos extintores. ", na qual a empresa tem feito esforços para economizar recursos naturais.

Nessa parte, foram feitas perguntas relacionadas às competências organizacionais da empresa, onde os encarregados citaram a flexibilidade e a inovação, que agregam valores à empresa. Quanto à sustentabilidade, um dos entrevistados, relatou a seguinte frase: "(...) que é ótimo trabalhar em empresas que praticam boas práticas".

A ética, também foi citada, como um grande diferencial para a empresa, pois já faz parte da cultura da empresa. Os encarregados relatam que devem saber identificar problemas e desenvolver soluções, aplicando os conhecimentos técnicos adquiridos, utilizando ferramentas e metodologias adequadas, visando gerar resultados apropriados, sendo necessário ter a capacidade de pensar estrategicamente e de tomar decisão acerca da melhor estratégia de implementação nas mudanças de processos de trabalho.

Relata o Supervisor ao citar algumas competências como: foco no cliente, flexibilidade, e afirma que, "a empresa, ela é capaz de atrair bons profissionais, e gerar bons profissionais", ou seja, oferece oportunidades a profissionais mais jovens e sem muita experiência, para se colocar no mercado de trabalho fazendo parte da equipe da empresa. Observando as competências organizacionais citadas através das entrevistas, percebe-se que apesar de ser uma empresa pequena, ela tem ações definidas, buscando e oferecendo a qualidade dos seus serviços, sendo flexível e comprometido com a sua marca. A organização depende de profissionais treinados, pessoas altamente especializadas e com considerável controle sobre seu trabalho. Nesta empresa há tecnoestrutura, visto que a padronização principal ocorre como resultado do treinamento que acontece fora e dentro da organização - nas universidades onde estes profissionais estudaram e através de treinamentos adquiridos dentro da empresa. 
Para Fleury e Fleury (2004), identificar as competências em setor organizacional e humano (essenciais e individuais) é um trabalho com muita criatividade. Além de agrupar com a gerência, é preciso considerar os conceitos dos clientes e conversar com os colaboradores de todos os níveis.

Nos entrevistados, foram observados em alguns a implicância na capacidade de mobilizar conhecimentos, habilidade e atitudes, tendo a qualidade de serem observados no comportamento diário, ou seja, ter iniciativa, trabalhando em equipe, foco nas decisões, criando e inovando se adequando à empresa. As competências individuais que as pessoas precisam para fazer parte do quadro da Alfa é ser ágil, dinâmica, pontual, demostrar habilidade, ter uma boa comunicação oral e escrita, ter equilíbrio emocional, conhecimento técnico, foco no seu trabalho e amor pela sua área. No Quadro 6, são apresentados os resultados obtidos em geral, onde as competências mais presentes foram relacionadas à relacionamento interpessoal, atenção, organização e dinamismo.

Quadro 6 - Competências Individuais da empresa Alfa

\begin{tabular}{|c|c|}
\hline \multicolumn{2}{|c|}{ COMPETÊNCIAS INDIVIDUAIS } \\
\hline \multirow{2}{*}{ Gerência/ Supervisor } & Liderança \\
& Tomada de decisão \\
& Planejamento organizacional \\
Influência \\
Encarregado & Equilíbrio Emocional \\
& Capacidade de avaliação \\
& Interagir com a Equipe \\
& Equilíbrio Emocional \\
& Responsabilidade \\
\hline Técnicos/Assistentes/Auxiliares & Relacionamento Interpessoal \\
\hline & Ética \\
& Determinação \\
& Equilíbrio emocional \\
& Organização \\
& Profissionalismo \\
\hline
\end{tabular}

Fonte: Autores (2016)

Os entrevistados responsáveis pelas áreas da organização não chegaram a um consenso no que se refere a competência mais importantes que o profissional precisa ter para fazer parte do quadro da empresa. Já os auxiliares e analistas afirmam que é, "a atenção e o trabalho em equipe". Já para a Diretoria, o principal é o Comprometimento.

Quanto às competências individuais, o gestor afirma que os colaboradores são comprometidos com o trabalho, e que a empresa possui profissionais competentes, quando comparado à concorrência. Quanto ao ambiente de trabalho, o Encarregado 1 respondeu que o ambiente é "saudável e se sente em família", já o auxiliar respondeu que " a equipe tem que ser mais unida, mesmo a pessoa não estando compatível com as atividades desenvolvidas, mas ela acaba se envolvendo com toda a empresa".

O Assistente argumenta que os colaboradores devem respeitar as pessoas, ter senso de responsabilidade, tanto no que se refere aos direitos, quanto aos deveres, tendo como parâmetro os valores éticos, capaz de interagir com as pessoas tanto de dentro como de fora da organização, além da pressão inerente à execução do trabalho.

Dessa forma, a partir da definição das competências individuais identificadas para a empresa, o presente estudo delineia as competências necessárias na empresa objeto deste estudo e que pode utilizar no gerenciamento de suas pessoas e das políticas adotadas visando atingir seu mercado. Segue o modelo de Competência sugerido para a empresa Alfa, como mostra a figura 3. 
Figura 3 - Árvore de Competência da empresa Alfa

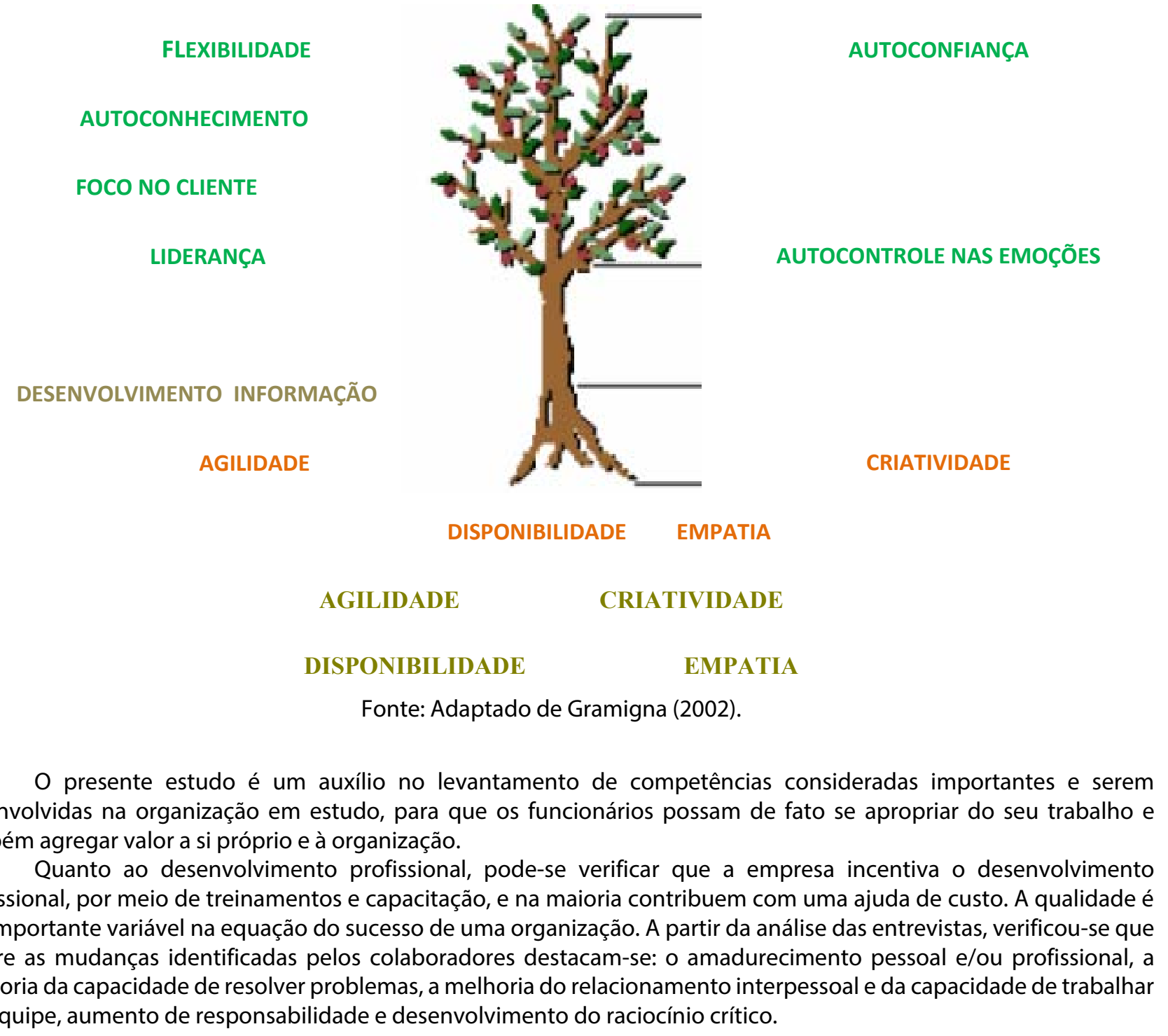

\section{CONSIDERAÇÕES FINAIS}

Para que haja uma modernização na gestão de pessoas, é necessário que ocorram mudanças significativas no comportamento das organizações. As estruturas centralizadas deverão ceder lugar à descentralização, e deverá haver, em todos os níveis da organização, pessoas capazes de pensar e executar múltiplas tarefas. É importante analisar as características de modernidade organizacional das empresas que adotam o modelo de gestão por competência, para que viabilizem e sustentem o mesmo (BARBOSA, 2008).

A implantação do modelo de gestão por competência necessita de planos estratégicos bem definidos, buscando o desenvolvimento do colaborador e da organização, aprimorando seus objetivos organizacionais e os pessoais. Portanto, o modelo de gestão procura desenvolver as competências, mapeadas com concisão, sendo a principal entrada para definir o modelo adequado para a definição do modelo de gestão por competência na Organização.

Pode-se verificar durante a pesquisa que a empresa não possui um planejamento de gestão sistematizado, entretanto, atualmente o gestor tem dado mais atenção à gestão e estratégia da organização, destacando-se maiores investimentos em seus produtos e serviços, valorizando por consequência sua marca. Nesse sentido, o modelo de gestão por competência aparece como uma alternativa, oferecendo às empresas uma maneira efetiva de alcançar seus objetivos organizacionais através do alinhamento da parte estratégica com as competências de seus funcionários.

As principais competências levantadas na pesquisa na empresa Alfa Ltda. foram: Competências Essenciais: Comprometimento; Competência Organizacional: Negociação, Sustentabilidade, Foco nos clientes e resultados, Inovação e flexibilidade; Competências Individuais: Capacidade de avaliação, Interagir com a Equipe, Equilíbrio Emocional, Responsabilidade, Liderança (GRAMIGNA, 2002).

As competências ora delineadas e avaliadas partem de um processo de priorização, que ocorre por família funcional. Portanto, os gestores são orientados a praticarem o feedback contínuo e a estarem sempre observando a 
entrega de competências das pessoas das quais farão a avaliação, porém a etapa de avaliação, em si, é composta por um momento para inserção da mesma no sistema, seguida por um momento de conversa entre avaliador e avaliado e concluída com a finalização no sistema. O mapeamento de competências, se utilizado como parâmetro na nomeação dos colaboradores, agregará maior aproveitamento do potencial humano, transformando cargos de confiança em cargos de competência, ampliando a valorização dos colaboradores e estimulando o desenvolvimento de relações maduras baseadas no profissionalismo (FLEURY; FLEURY, 2004)

A implantação do modelo de Gestão por Competência na empresa Alfa Ltda., proporcionou o desenvolvimento das competências individuais e organizacionais em conjunto, principalmente, porque o objetivo de inserção desse sistema está voltado para o atendimento das estratégias empresariais, focando nos resultados esperados para conseguir a vantagem competitiva. Ao analisar os aspectos críticos, constatou-se que há alguns traços em comum entre as empresas, capazes de influenciar no modelo de gestão (GRAMIGNA, 2010).

Pode-se destacar que as dificuldades na empresa Alfa estão relacionadas a fatores como: falta de clareza do conceito de competência, a desarticulação do modelo em relação aos subsistemas de gestão de pessoas, a complexidade de operacionalização dos modelos de Gestão de Competências, ao fraco embasamento conceitual para a definição de competências organizacionais, a falta de alinhamento das competências individuais às organizacionais e ao não envolvimento de todos os níveis hierárquicos na implementação do modelo.

Entretanto, espera-se que a partir da implantação do sistema de gestão obter-se-á um quadro funcional mais qualificado e produtivo, o gerenciamento procurará adaptar-se às competências necessárias, as habilidades e os conhecimentos para habituar e obter melhores desenvolvimentos de cada indivíduo e da organização, sendo de grande importância o mapeamento das competências para o crescimento da empresa Alfa.

O uso de recursos estratégicos, para a implantação, seleção, treinamento e avaliação o responsável consegue tomar decisões, resolver os problemas internos aumentando a produtividade da empresa. A partir da pesquisa, evidenciam-se como sugestões a serem dadas para a empresa: Participação para o processo de formulação das práticas e sugestões para o novo modelo de gestão para ser aplicado na empresa; Implementar um programa de avaliação contínua para ascensão dentro da empresa, através de um plano interno de cargos e salários; Desenvolvimento de competências por meio de cursos de capacitação; Avaliar de forma sistemática os colaboradores por meio do modelo de competências a ser implantado. É relevante propor sugestões para estudos futuros como: fazer comparação das competências levantadas e outras organizações do mesmo ramo de atividades; propor um sistema de avaliação de competência $360^{\circ}$ em organizações de pequeno porte; avaliar as competências funcionais voltadas para resultados em empresas de pequeno porte; propor outros modelos de definição de competências em empresas de pequeno porte.

Entre as limitações encontradas do presente estudo foi a realização da pesquisa durante o expediente do trabalho, sendo interrompida diversas vezes para a execução das atividades dos entrevistados, o que pode ter comprometido as respostas. Outra limitação é no que se refere a pesquisa com os colaboradores da área operacional, que apresentam baixa escolaridade e a entrevista possuir perguntas que exigiam um grau maior de interpretação.

Como a empresa Alfa Ltda. tem o Modelo Empreendedor de Gestão, com uma pequena tecnoestrutura, pouca função administrativa que formata o fluxo operacional e especialização horizontal simples, pode-se dizer que à medida que a empresa for se desenvolvendo poderá apresentar uma nova configuração organizacional, possivelmente com uma forte dose de tecnoestrutura e padronização dos processos. O modelo de gestão ora proposto necessita da cooperação dos envolvidos, principalmente, por parte dos gestores, para o maior conhecimento dos processos que estejam alinhados aos objetivos organizacionais, com as competências técnicas e comportamentais, sendo necessário evoluir e pensar estrategicamente, daí a importância do alinhamento do CHA com a estratégia da empresa (CARBONE, 2006).

\section{REFERÊNCIAS}

BARBOSA, Catarine Aparecida Vieira. Aspectos críticos da implementação do modelo de Gestão por Competências em duas empresas de manufatura. 2008. 146 p. Dissertação (Mestrado em Gestão de Negócios) - Universidade Católica de Santos - Unisantos, Santos, 2008.

BRANDÃO, Hugo Pena e GUIMARÃES, Tomás de Aquino. Gestão de Competência e Gestão de Desempenho: Tecnologias distintas ou instrumentos de um mesmo construto? Revista de Administração de Empresas, São Paulo, v. 41, n. 1, p. 8-15, jan./mar. 2001.

BORGES-ANDRADE, G.; ABBAD, G.; MOURÃO, L. (Org.). Treinamento, desenvolvimento e educação em organizações e trabalho: fundamentos para a gestão de pessoas. Porto Alegre: Artmed, 2006.

CARBONE, Pedro Paulo. Gestão por competência e Gestão do Conhecimento. 2. ed. Rio de Janeiro: Editora FGV, 2006. 
CARVALHO, Felipe Marcelo Gonzaga de. Gestão por competência no serviço público.[2011] Disponível em <http://acervodigital.ufpr.br/bitstream/handle/1884/33683/FELIPE\%20MARCELO\%20GONZAGA\%20DE\%20CARVALHO .pdf? sequence=1>. Acesso em: 22 maio 2017.

COOPER, D.; SCHINDLER, P. Métodos de Pesquisa em Administração. 7. ed. São Paulo: Bookman, 2006.

DUTRA, Joel Souza. Gestão por Competência: um modelo avançado para o gerenciamento de pessoas. 5. ed. São Paulo: Editora Gente, 2001.

Competências: Conceitos Instrumentos Gestão. São Paulo: Editora Atlas S. A., 2004.

. Competências: Conceitos e Instrumentos para a Gestão de Pessoas na Empresa Moderna. São Paulo: Editora Atlas S. A., 2008a.

Competências: Conceitos, Métodos e Experiências. São Paulo: Editora Atlas S. A., 2008b.

Atlas, 2012.

Competências: Conceito e Instrumentos para a Gestão de Pessoas na Empresa Moderna. São Paulo: Editora

FRANÇA, Ana Cristina Limongi. PRH- Práticas de Recursos Humanos: Conceitos, Ferramentas e Procedimentos. São Paulo: Editora Atlas S. A., 2009.

FLEURY, A. C. C.; FLEURY, M. T. Estratégias empresariais e formação de competências. 3. ed. São Paulo: Atlas, 2004.

Estratégias empresariais e formação de competências: um quebra-cabeça caleidoscópico da indústria brasileira. 3. ed. São Paulo: Atlas, 2006.

. Estratégias Empresariais e formação de Competência: Um quebra cabeça caleidoscópico da indústria brasileira. 3. ed. São Paulo: Atlas, 2011.

GABRIEL, Sergio. A influência da micro e pequena empresa no desenvolvimento econômico do Brasil. Web Artigos. 2009. Disponível em: < http://www.webartigos.com>. Acesso em: 13 maio 2009.

GIALDINO, I. V. Estrategias de investigacion cualitativa. Barcelona: Gedisa, 2014.

GIL, Antônio Carlos. Gestão de Pessoas: Enfoque nos papéis profissionais. São Paulo: Atlas S. A., 2010.

GRAMIGNA, Maria Rita. Modelo de competências e gestão dos talentos. São Paulo: Pearson Education do Brasil, 2002.

. Modelo de competências e gestão dos talentos. 2. ed. São Paulo: Pearson Prentice Hall, 2007.

. Gestão de Pessoas: Enfoque nos papéis profissionais. São Paulo: Atlas S. A., 2010.

HAMEL, G.; PRAHALAD, C. K. Competindo pelo futuro. Rio de Janeiro: Campus, 1995.

LAVILLE, C.; DIONNE, J. A construção do saber: manual de metodologia da pesquisa em ciências humanas. Porto Alegre: Editora Artes Médicas Sul Ltda.; Belo Horizonte: Editora UFMG, 1999.

LEME, Rogério. Aplicação prática de gestão de pessoas por competências: mapeamento, treinamento, seleção, avaliação e mensuração de resultados de treinamento. Rio de Janeiro: Qualitymark, 2005.

MARCONI, M. A.; LAKATOS, E. M. Técnicas de pesquisa: planejamento e execução de pesquisas, amostragens e técnicas de pesquisa, elaboração, análise e interpretação de dados. 5. ed. São Paulo: Atlas, 2002.

PERRENOUD, Philippe. Dez Novas Competências para Ensinar - Convite à Viagem. Porto Alegre: Artmed, 2000.

RICHARDSON, Roberto J. Pesquisa Social: métodos e técnicas. 3. ed. São Paulo: Atlas, 2009. 
RODRIGUEZ Y RODRIGUEZ, Martius. Classificando competências. [2002]. Disponível em: <http://www.rh.com.br/Portal/Desempenho/Artigo/3250/classificando-as\%20compet\%C3\%AAncias.\%20html >. Acesso em: 20 ago. 2014.

SERVIÇO BRASILEIRO DE APOIO ÀS MICRO E PEQUENAS EMPRESAS DE SANTA CATARINA (SEBRAE). Critérios de classificação de empresas - ME - EPP. 2007a. Disponível em: <http://www.sebraesc.com.br/leis/default.asp?vcdtexto=4154>. Acesso em: 24 set. 2013.

SERVIÇO BRASILEIRO DE APOIO ÀS MICRO E PEQUENAS EMPRESAS DE SANTA CATARINA (SEBRAE). Critérios de classificação de empresas - ME - EPP. 2007b. Disponível em: <http://www.sebraesc.com.br/leis/default.asp?vcdtexto=4154>. Acesso em: 24 set. 2014.

SERVIÇO BRASILEIRO DE APOIO ÀS MICRO E PEQUENAS EMPRESAS DE SANTA CATARINA (SEBRAE). Estudos e Pesquisas. 2014. Disponível em: <http://www.sebrae.com.br/customizado/estudos-e-pesquisas >. Acesso em: 26 set. 2015.

TRIVIÑOS, Augusto N. S. Introdução à pesquisa em ciências sociais: a pesquisa qualitativa em educação. São Paulo: Atlas, 1987.

VERGARA, S. C. Projetos e relatórios de pesquisa em administração. 3. ed. São Paulo: Atlas, 2000.

VILAS BOAS, A. A.; ANDRADE, R. O. B. Gestão Estratégica de Pessoas. Rio de Janeiro: Elsevier, 2009.

YIN, R. K. Estudo de Caso: planejamento e métodos. 3. ed. Porto Alegre: Bookman, 2005.

. Estudo de Caso: planejamento e método. 5. ed. Porto Alegre: Bookman, 2015. 